\title{
Investigating The Cause Of High Attrition Rates In Women Employees Of Private Organization
}

\author{
Fahad Abdali \\ Department of Public Administration \\ University of Karachi \\ M. Abuzar Wajidi \\ Barrett Hodgson University \\ Karachi \\ Faraz Ahmed Wajidi \\ Institute of Business and Health Management (IBHM) \\ Dow University of Health Sciences
}

\begin{abstract}
The main purpose of this study is to investigate the factors and causes of high attrition rates in women employees working in private Organizations. The emphasis of this research is placed on factors and its impact on the decision of women for attrition. The research is quantitative in nature and data that is collected for this research using primary information which has been gathered through using survey questionnaire. The analysis of data is conducted using Smart-PLS. The results of this particular study conclude that uncongenial Organizational culture, insufficient compensation, job satisfaction and social Organizational practice have a significant impact on attrition of women working in private Organizations. The implications of this research include that the atmosphere in most of the Organizations are tough and overwhelming for women who have to manage their work as well as their responsibilities towards families and children.
\end{abstract}

Keywords: High Attrition Rates in Women Employees, Private Organization.

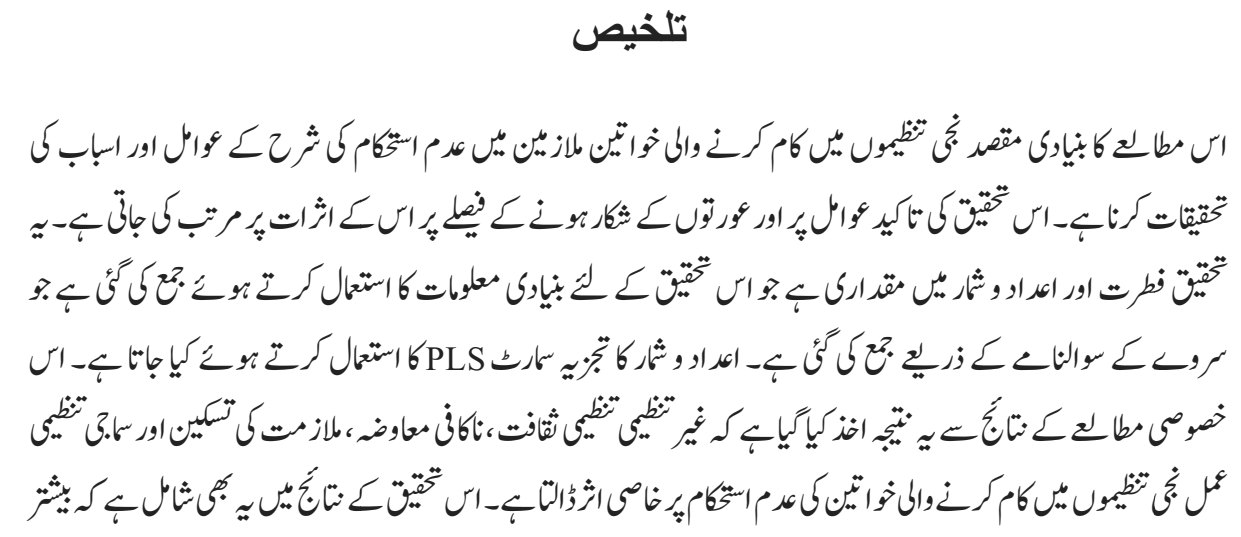

This work is Licensed under a Creative Commons Attribution-NonCommercial 4.0 International License (c) () () 


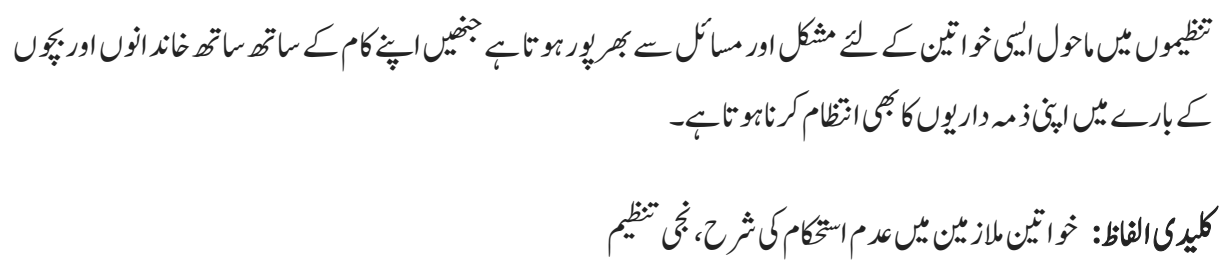

\section{Introduction}

According to Siebert and Martin (2016), organizations are made with people. The recent years witnessed a tremendous increase in the population of female workforce in private organizations (Carson et.al, 2016). Over these past few years, women have excelled incredibly in all spheres of life. Contributions of women are at par as much as by men towards the national economy (Locke, 2016). Increased presence and contribution of women workforce in the organization have significantly brought transformation from traditional working roles. In the present era, women are very optimistic and are striving for better and advanced position in the organization just like male employees with relatively a higher aspiration. Despite this enthusiastic approach, many women employees face several challenges that create numerous hurdles for them to continue their jobs (Ibarra and Petriglieri, 2016). Primarily, in our society, women are subject to dual responsibility of ensuring income generation and family well-being at the same time (Neal \& Hammer, 2017).

The fundamental aim of human resource management is to facilitate an Organization to achieve its goals through retaining, managing and recruiting employees (Gupta, Kumar and Singh, 2014). In accordance with the research of Ko \& Hur (2014), globalisation has enabled several companies to expand and grow their businesses in various markets. The expansions also require Organizations to recruit and retain valuable staff and efficient employees. According to the research of Masvaure, Ruggunan \& Maharaj (2014) one of the biggest concerns of Organization in effectively expanding is the attrition rate. Attrition rate is considered as the total number of employees that have left the Organization. Based on the research of Irefin \& Mechanic (2014), the rate of attrition is presented in the form of percentage that represents the employees who have been lost by the Organization for any given reason within a specified duration. On the other hand, the research of Masvaure, Ruggunan \& Maharaj (2014) have discussed it as the reduction of employers within a company in regards with numbers or size. The reduction of these employees could happen either through layoff, resignation, or even retirement.

Increase women employee attrition springs up as a vital issue in the private sector (Ahlin, Ericson $\square$ Lidman, Norberg \& Strandberg, 2015). Over the span of few years, women employee attrition is becoming one of the most critical problems especially in the private sector. Many married women are seen working day and night for their family and society to efficiently support their family. However, at the organization level, no safety measures are in place for women employees dedicating their maximum time to work and society 
(Dalle Grave et al., 2015). This and many such hurdles make it difficult for women to continue their career in their choice of profession. Despite countless efforts, women employee attrition rate has been seen increasing organization costs and creating intractable challenges in the organization. This research intends to analyse several causes and reasons for women employee attrition in the private sector. Outcomes and findings of the research from the responses will elaborate the true aspect of increased women attrition rate and identify the main causes of high attrition rate among female workforce especially in the private organization.

According to the research of Irefin \& Mechanic (2014), attrition is a term that refers to the termination of employees, which could either be involuntary or voluntary. It includes reason such as retirements or deaths that results in the lower count of physical workforce. There are a few forms of attrition that each business experience and has been regarded as the most complicated and sensitive concern of businesses across the world (Fox \& Quinn, 2015). However, it has been highlighted in the research of Siebert \& Martin (2016) that the rate of employee turnover cannot be evaluated easily as it varies from one company to the other. In addition to this, analysing the rate of attrition is not only associated with the presentation of a mathematical equation, it is linked with the concerns that root back to the process of hiring. It has been noted in the research of Sarkar, Sahoo \& Klasen (2019) that most of the companies do not take cost of hiring and turnover into account when strategizing their human resource despite its significance. The research of Seidler et al (2014) emphasises that such human resource management strategies are required to be developed considering the nature of Organizations as well as the job for which a candidate has been selected.

There are two main kinds of attrition, good and bad. According to the research of Olowokere. Chovwen \& Balogun (2014) good attrition include lesser number of employees leaving the Organization, implying that it is beneficial for the Organization if employees with lower productivity levels leave voluntarily. In accordance with the research of Masvaure, Ruggunan \& Maharaj (2014), the continued services of employees who have low productivity levels are likely to adversely impact the profitability and productivity of the company. In addition to this, the research of Sarkar, Sahoo \& Klasen (2019) indicates that employees who spend their lifetime in a single company often secure higher positions and huge salary package, which for the Organization is a high labour cost. Furthermore, the research of Siebert \& Martin (2016) concluded that with the old employees leaving the company voluntarily, the opportunities are given to the new talent and recruits, who brings in the new attitudes, abilities, approaches and ideas.

Among many other benefits of good attrition, it is found in the research of Ahlin et al. (2015) that termination is one of the methods to let go of the employees whose presence would cause harm to the performance of Organization as a whole. According to the 
research of Olowokere. Chovwen \& Balogun (2014), it facilitates the Organization in hiring new recruits, progress the Organization through effective measures, build teams that are high performance, and share the rewards with employees that are beneficial for the company and are deserving.

However, the study of Williams, Berdahl \& Vandello (2016) indicated that bad attrition is the form in which employees with high performance and productivity leave the Organization. Most of these attritions occur because of the stress, workload, or the requirement of the market. Considering the notion of market driven attrition, it has been observed that employers often make changes such as offering good packages with improved benefits. According to the research of Gupta, Kumar \& Singh (2014), most of the stress driven attrition occurs when the workload is extensive, and performers are lesser in quantity. Hence, it can be said that attrition has always been existed in all Organization for a very long time. There is a high rate of women employee attrition in many Organizations, which is a result of many factors collaboratively. In order to understand these elements, it is essential to determine these elements that increases the rate of attrition among women employees working specifically in private Organization. Moreover, it is essential to discuss the strategies of human resource management to retain these women employees, which includes the push and pull factor for the same.

It has been noted in various researches like Gupta \& Bhaskar (2016)that work life balance is one of the most significant and prominent elements that can potentially lead an employee to stay or leave the Organization. It is even more prominent in the cases of female employees, as highlighted in the research of Williams, Berdahl \& Vandell(2016) because women are expected to balance their work and home perfectly. In addition to this, the research of Ahlin et al (2015) highlights that work environment and atmosphere holds greater significance in the case of women as most of the women have experienced undermining from their immediate reporting authorities or supervisor. Patriarchal environment within a work force can lower the motivation of female employees and may cause them to leave the company, despite their high levels of skills (Siebert \& Martin, 2016).

\section{Review of Literature}

According to the research of Gupta \& Bhaskar (2016). Attrition rate is relatively higher in the private sector than the attrition rate at any other sector. It has also been found out that successful implementation of work life balance creates an efficient working environment which sufficiently decreases the stress level. Proper balance between work life balances provides a platform for lesser probability of accidents and greater productivity in organizations (Fox \& Quinn, 2015). 
The literature on attrition of employees accommodate numerous researches such as Seidler et al (2014) that focused on elements that increase its rate. These elements were further classified into groups based on the characteristics, such as slow career growth, monetary considerations, lack of opportunity, intense workload, in effective communication, and stress. According to the research of Korsakiene et al., (2015) ineffective communication about the job description or task may lead to the misjudgement of the outcome. Moreover, the research of Irefin \& Mechanic (2014) indicate that ineffective communication lead to unjustified expectations among employees which can further result adversely on the growth and performance of the Organization.

In accordance with the research of Siebert \& Martin (2016) monotonous routine can cause lower motivation levels among workers. It lacks challenge within the job and thus, it causes younger workers to feel bored once they have made themselves familiar with. In addition to this, the research of Saeed et al. (2014) concluded that high rate of attrition occurs in Organizations where opportunities and learning curve is insufficient or lacking. It has been noted in the research of Peltokorpi, Allen \& Froese (2015) that most of the employee's report leaving Organizations because of the lack of opportunities.

In addition to this, it has been found through the research of Terera \& Ngirande (2014) that it is essential for the collaboration and compatibility of employee with the job description and working environment in order to increase the performance of Organization. In addition to this, the research of Seidler et al (2014) indicates that mismatch of skills with the job cause negative outcome. However, the compatibility is not evaluated solely on the basis of the skills an employee has but also with his attitudes towards learning and performing the task. The research of Ahlin et al. (2015) suggests that working for a job that does not match the skillset of the worker is likely to increase frustration and eventually lead up to attrition. It has been noted in the research of Haque \& Yamoah (2014) that employees are likely to perform better in companies and Organizations where they are given with tasks that they enjoy doing.

According to the research of Gupta, Kumar \& Singh (2014), the lack of balance between work and life causes stress among workers and creates hurdles in being effectively productive. Most of the employees tend to leave the Organization where they are overburdened with work while having little to no time for themselves to relax (Williams, Berdahl \& Vandello, 2016). On the other hand, the research of Irefin \& Mechanic (2014) highlights that the demands of employees are escalating with the passage of times, which is considered as a result of the high competitive market and the competitive salaries that are being offered to individuals with adequate skills. It implies that competitive salaries and packages can be considered as the contributing factors towards attrition of employees. It has been noted in the research of Saeed et al (2014) that shift timings and work duration are the two most common factors that mostly contribute in the high rate of 
attrition. In some companies, employees are required to stay in the office till late hours to address foreign clients. According to the research of Olowokere. Chovwen \& Balogun (2014), most of the women employees face difficulties in staying late in the office and often experience issues in convincing their families for the same. It further causes them to leave the company.

The research of Mohanty \& Jena (2016) suggests that monetary benefits are not the sole attracting aspect, working environment play a key role in retaining the employees. It has been noted that employees are likely to leave an Organization where they experience lack of fairness and justice. Moreover, the research of Ibarra \& Petriglieri (2016) have highlighted that few contributing aspects in attrition of employees because of working conditions include environmental concerns, lack of leadership, lack of effective measures in dealing grievances, lack of care for employees, lack of safety of employees, and lack of trust among managers and employees.

In accordance with the research of (Neal \& Hammer, 2017), it has been found that lack of career growth, opportunities and challenges as major elements that causes attrition of employees. Most of the employees stay within the company as it lures them for the opportunity of growth and challenging environment. According to the findings of Eikhof (2016) employees tend to prefer challenging work environment as compared to the monetary benefits they seek from a company. However, it has been noted that attrition escalates where the Organization hires external talent on higher positions, while ignoring the internal employees who might be able to handle the added responsibilities. According to the research of Sarkar, Sahoo \& Klasen (2019), this adds to the de-motivation of employees as they perceive it as a lack of growth within the Organization.

It has been found through the research of Locke (2016) many women are seen working in various organizations with the purpose to generate income to support their families while simultaneously taking care of their household chores and children's responsibility. In many cases, women are seen continuing their jobs following child births. However, this creates multiple difficulties for them to maintain the balance between work and house life (Neal \& Hammer, 2017). Moreover, women are often seen with increased stress in managing the balance between parenting and professional responsibilities. Increased stress and many such factors collectively contribute in elevating job turnover or attrition rate in case of women employees. This research intends to investigate the main causes of high attrition rate in women employees (Carson et.al, 2016). This research will outline several factors that compel females to leave or quit their jobs. However, this research specifically focuses on the private sector. 


\section{Hypotheses}

H1: Uncongenial Organizational Culture has a significant impact on Attrition

H2: Insufficient Compensation has a significant impact on Attrition

H3: Job Satisfaction has a significant impact on Attrition

H4: Social Organizational Practice has a significant impact on Attrition

\section{Research Methodology}

The research methodology refers to the systematic plan to conduct a research in order to provide results or conclusion. According to the research of Brannen (2017), research methodology comprises of processes which include process of data collection, process of selecting sample size, and process of data analysis. In order to understand the factors that cause high rate of women attrition in private Organizations, this research has used quantitative research methods. The information has been obtained through primary methods of data collection using a well-structured, closed-ended survey questionnaire, which has been developed to essentially investigate the factors that contribute in attrition of female employees. In addition to this, data obtained from secondary methods has also been included in the literature review to reflect on the causes that contribute in high rate of attrition of women employees. The data has been collected from 50 women who have been worked in more than one company. These women were selected using random sampling technique to identify the factors that encouraged them to leave their respective companies. The data has been analysed by using SPSS statistical technique. Furthermore, the findings of this research are discussed in the light of literature to develop understanding of these factors causing high rate of attrition among women employees in Organizations.

\section{Research Model}

For this particular research, following model is used to illustrate the research objective and outcome.

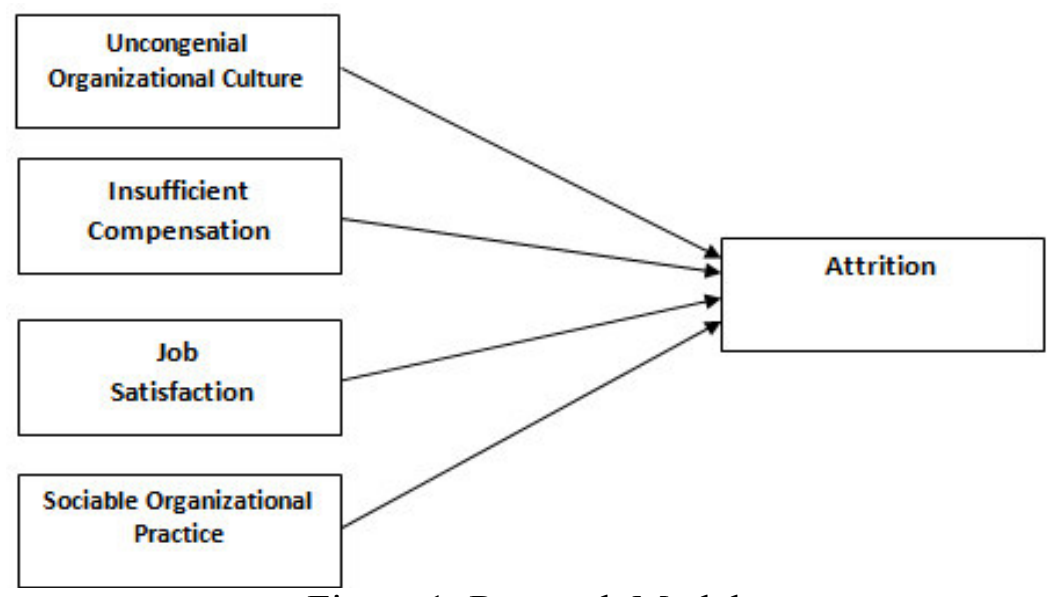

Figure 1: Research Model 


\section{Discussion}

In accordance with the research of Robinson et al (2014) the theory of job embeddedness accommodates multiple factors and elements that can potentially influence an individual to stay or to leave the Organization for which he or she works in. Most of these elements are associated with the factors a person experiences during his working tenure within the Organization. One of the prime elements that fall under as its example is the behaviour of co-worker and social environment. In addition to this, it includes the working conditions, the compatibility of job and the skills required as well as the contribution that an Organization makes for the society as a whole. According to the research of Kiazad et al (2015), the notion of job embeddedness theory also extends towards the personal reasons, community commitments, family pressure, and other relationship conflicts.

The purpose of this theory is to understand the factors and causes that compel employees to leave the company. Understanding the root causes enable human resource department to make strategies to retain these employees and optimise their productivity while providing them leverage to balance their lives. In accordance with the research of Karatepe \& Shahriari (2014) employees are considered to be the individuals who are interlinked with various parts and aspects of life, and hence, require the entire surrounding to be favourable for them. Furthermore, it has been noted that the job embeddedness of an individual is associated with the factors that influence the experience as well as the decision-making process of an individual in regards with his or her career. In addition to this, in such cases, the individual finds himself or herself in the centre of all the connections. The research of William Lee, Burch \& Mitchell (2014) highlights that there is always a certain amount of disruption associated with leaving the job. Therefore, individuals who have higher embeddedness with their jobs and careers are likely to experience a higher disruption and hence, would avoid making decisions to leave the job. On the other hand, employee who tend to have fewer relationships, responsibilities, and roles are likely to be ones with lower job embeddedness. In addition to this, these are the individuals who tend to possess lower connections around them. In such cases, these individuals are difficult to be retained and are likely to leave the job if they think is not as per their requirement.

\section{Empirical Findings and Analysis}

The purpose of this research is to investigate the main causes of high attrition rate in women employees. This research has also outlined several factors that compel females to leave or quit their jobs. However, this research specifically focuses on the Organizations belonging to private sector. Primarily, the research has applied Smart PLS as the statistical model to investigate the results of this research that has been construed in the form of research hypotheses. For this particular research, quantitative research method 
has been selected. With the help of quantitative research method, primary quantitative data has been intended to collect from the selected sample size. A well-structured questionnaire has been formed to find causes of women employees' attrition.

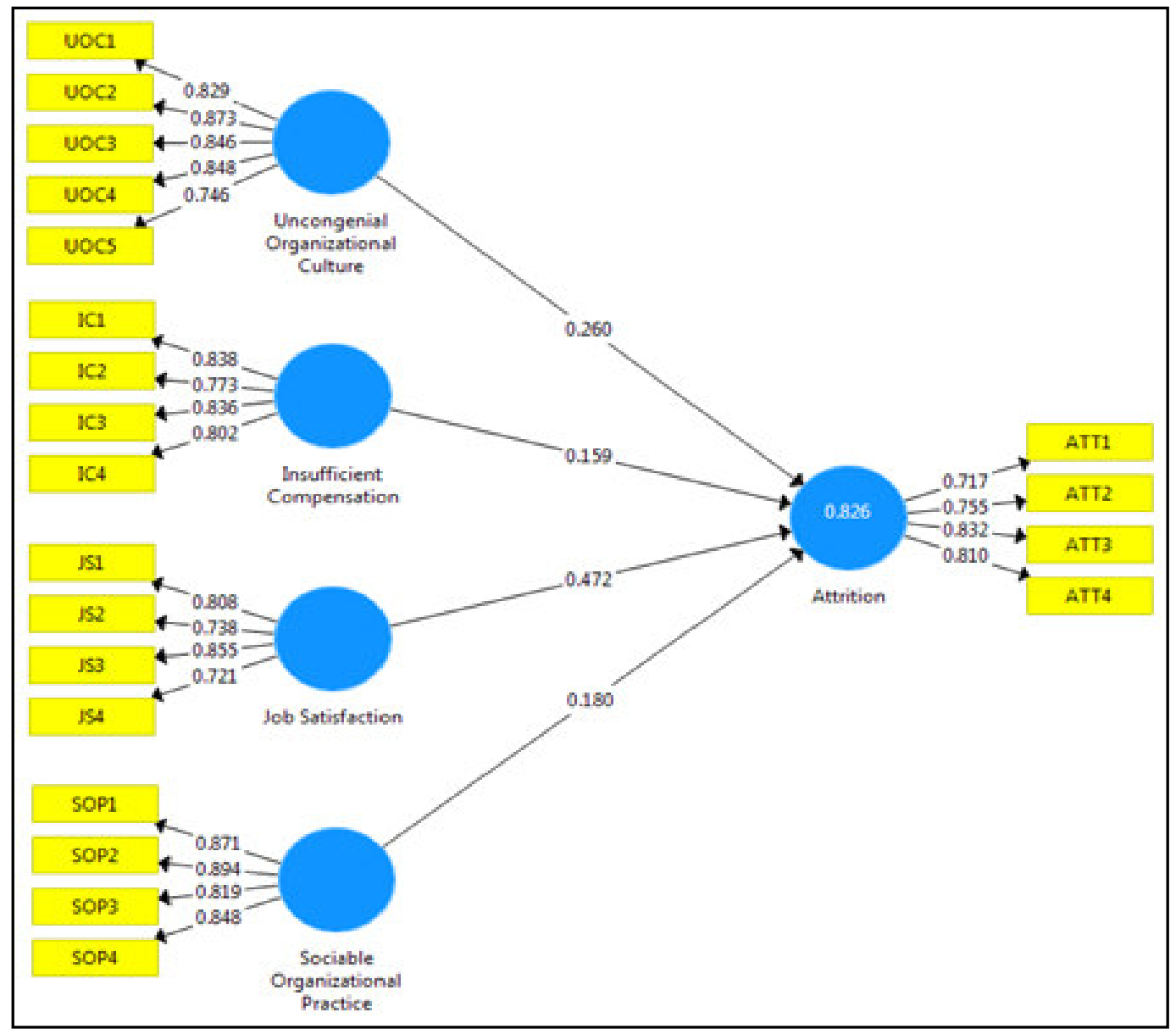

Figure 2: Smart PLS Statistical Model

\section{Factor Loadings Significant}

The table below represents significant of factor loading which involves 21 factors that are based on 5 variables for this research. The research and the findings of this table indicates that higher value that is associated with the absolute value of factor loading is directly proportional to the contribution of that particular variable on the factor. The following table presents 21 components that have been used to evaluate the impact of variables as the whole. Furthermore, the factor loading value of each of the component and the variable is required to be 0.5 or more in order to be acknowledged as approved. 
Table: 1

Factor loadings significant

\begin{tabular}{|c|c|c|c|c|c|}
\hline Options & Attrition & $\begin{array}{c}\text { Insufficient } \\
\text { Compensation }\end{array}$ & $\begin{array}{c}\text { Job } \\
\text { Satisfaction }\end{array}$ & $\begin{array}{c}\text { Sociable } \\
\text { Organizational } \\
\text { Practice }\end{array}$ & $\begin{array}{c}\text { Uncongenial } \\
\text { Organizational } \\
\text { Culture }\end{array}$ \\
\hline ATT1 & 0.717 & & & & \\
\hline ATT2 & 0.755 & & & & \\
\hline ATT3 & 0.832 & & & & \\
\hline ATT4 & 0.810 & & & & \\
\hline IC1 & & 0.838 & & & \\
\hline IC2 & & 0.773 & & & \\
\hline IC3 & & 0.836 & & & \\
\hline IC4 & & 0.802 & & & \\
\hline JS1 & & & 0.808 & & \\
\hline JS2 & & & 0.738 & & \\
\hline JS3 & & & 0.855 & & \\
\hline JS4 & & & 0.721 & & \\
\hline SOP1 & & & & 0.871 & \\
\hline SOP2 & & & & 0.894 & \\
\hline SOP3 & & & & 0.819 & \\
\hline SOP4 & & & & 0.848 & \\
\hline $\mathrm{UOC} 1$ & & & & & 0.829 \\
\hline UOC2 & & & & & 0.873 \\
\hline UOC3 & & & & & 0.846 \\
\hline UOC4 & & & & & 0.848 \\
\hline UOC5 & & & & & 0.746 \\
\hline
\end{tabular}

\section{The Convergent Validity}

It has been noted in the research of Hair et al. (2013) convergent validity is a theory that combines multiple elements and variables and collaborate them to investigate a concern or a matter. It could either be an issue, concept or hypotheses. It is essential for the researcher analyse the convergent validity for the research in order to investigate on the values that have already been reflected through the table of factor loadings, average variance and composite reliability extracted. The research of Melchers \& Beck (2018) concludes that factor loading of items should be more than 0.6 in value in order to be statistically significant. In addition to this, the value of AVE or Average Variance Extracted and CR or Composite Reliability is required to be above 0.5 and 0.7, respectively. From the findings of the research in table below, each of the value resented is above the respected threshold. It means that all of the factors and variables have higher level of reliability, consistency and validity. 
Table: 2

Reliability \& Validity

\begin{tabular}{|l|c|c|c|c|}
\hline \multicolumn{1}{|c|}{ Options } & $\begin{array}{c}\text { Cronbach's } \\
\text { Alpha }\end{array}$ & rho_A & $\begin{array}{c}\text { Composite } \\
\text { Reliability }\end{array}$ & $\begin{array}{c}\text { Average } \\
\text { Variance } \\
\text { Extracted (AVE) }\end{array}$ \\
\hline Attrition & 0.783 & 0.784 & 0.861 & 0.608 \\
\hline Insufficient Compensation & 0.830 & 0.848 & 0.886 & 0.66 \\
\hline Job Satisfaction & 0.793 & 0.829 & 0.863 & 0.612 \\
\hline $\begin{array}{l}\text { Sociable Organizational } \\
\text { Practice }\end{array}$ & 0.881 & 0.895 & 0.918 & 0.737 \\
\hline $\begin{array}{l}\text { Uncongenial Organizational } \\
\text { Culture }\end{array}$ & 0.887 & 0.898 & 0.917 & 0.688 \\
\hline
\end{tabular}

\section{The Structural Model (Inner Model) or Hypothesis Testing}

The inner measurement of the structural model or in other words, the hypotheses testing for this research has been carried out using the outer measurement model. The evaluation and the testing of hypothesis have been carried out through structural equation modelling using Smart PLS or Partial Least Square 3.2.4. The purpose of using Smart PLS is to investigate complicated model and to produce results associated with it, as indicated by the research of Ringle, Wende \& Becker (2015). The inner model is tested through bootstrapping of 5000 sub samples along with the methods of re-sampling.

Table: 3

Hypotheses Testing

\begin{tabular}{|l|c|c|c|c|c|}
\hline \multicolumn{1}{|c|}{ Options } & $\begin{array}{c}\text { Original } \\
\text { Sample (O) }\end{array}$ & $\begin{array}{c}\text { Sample } \\
\text { Mean (M) }\end{array}$ & $\begin{array}{c}\text { Standard } \\
\text { Deviation } \\
(\text { STDEV })\end{array}$ & $\begin{array}{c}\text { T Statistics } \\
(\mid \mathrm{O} / \text { STDEV|) }\end{array}$ & P Values \\
\hline $\begin{array}{l}\text { Insufficient Compensation - } \\
\text { > Attrition }\end{array}$ & 0.159 & 0.161 & 0.055 & 2.906 & 0.004 \\
\hline Job Satisfaction -> Attrition & 0.472 & 0.474 & 0.031 & 15.389 & 0.000 \\
\hline $\begin{array}{l}\text { Sociable Organizational } \\
\text { Practice -> Attrition }\end{array}$ & 0.18 & 0.177 & 0.05 & 3.628 & 0.000 \\
\hline $\begin{array}{l}\text { Uncongenial } \\
\text { Organizational Culture -> } \\
\text { Attrition }\end{array}$ & 0.26 & 0.259 & 0.05 & 5.175 & 0.000 \\
\hline
\end{tabular}

This research has been conducted to evaluate five hypothesis and to investigate whether or not they are accepted. The acceptance or rejection of these hypotheses are investigated through evaluating the value of $\mathrm{P}$. Values of $\mathrm{P}$ that are below 0.05 indicate hypotheses that are accepted, while the values of $\mathrm{P}$ that are above 0.05 are considered as rejected hypotheses. Considering the values in the table above. It can be found that all the values of $\mathrm{P}$ for all hypotheses are below 0.05 which means that these hypotheses are accepted. 
Hence, it can be found that Uncongenial Organizational Culture, Insufficient Compensation, Job Satisfaction and Social Organizational Practice has a significant impact on Attrition of women working in private Organizations.

\section{Conclusions}

The findings of this research conclude that Attrition is becoming one of the biggest problems faced by the private organizations. This research paper intends to determine the factors that affect retention of women employees in private organization. For this particular research, only female workforce has been focused and specifically in the private organizations. The study reveals several factors that contribute to affect retention of female employees in organization (Fox \& Quinn, 2015). Role of women in the development and growth of any country can never be underestimated but at the same time it is important to understand who they are bound towards dual responsibility towards work and family. Therefore, work life balance policies should be implemented and promote to bring harmony to work and life accordingly (Eikhof, 2016).

The findings of this research indicate that uncongenial Organizational culture has a significant impact on attrition. Women employee attrition depends upon several factors like work profile, job posting, better career opportunities, personal causes and compensation (Fox \& Quinn, 2015). Today, women are more in jobs and it is becoming quite challenging for them to create and maintain a good balance between work and family responsibilities. Besides providing financial support, female are held responsible for taking care of elderly parents and their children's (Williams, Berdahl \& Vandello, 2016). As the societal pressure is so intense, many female fail to maintain the balance so they end up leaving or quitting their job. Organizations in this regard needs to focus on sophisticated work life policies in order to successfully retain women employees. Nilsen, Skipstein \& Demerouti (2016) indicated that work life policies are the base level indicators in organization prioritizing family over work or work over family. Organizations must offer sufficient leaves and flexible work scheduling to their women employees so they can create a good balance between work and family (Eikhof, 2016). Organization needs to implement work life balance policies to radically reduce turnover rate and retain potential employees for a longer period of time in an organization (Mohanty \& Jena, 2016).

In addition to this, the findings of this research indicates that insufficient compensation has a significant impact on attrition, implying that employees are likely to leave a company if the compensation for their hard work is insufficient. It has been observed through the research of Micke (2015) that most of the employees in corporate culture are impacted by the Organizational influence when it comes to deciding to leave the company. Organizations that acknowledge the hard work of their employees and pay them respect are able to retain their employees for a longer period of time. In addition to this, the research of Rubel \& Kee (2015) suggested that the employees are required to be given compensations, rewards, perks, and benefits to increase their motivation and will to perform their duties with zeal. It has been highlighted in many studies like Adeoye and 
Fields (2014) an individual towards the Organization and its goals. The compensation package usually includes bonus, increments, pay and promotion, or in some cases, it is the combination of all. Moreover, it has often been found that the lack of acknowledgement and adequate compensation or promotion in regards with the regular work results in increased turnover rate within the Organization. In some cases, employees are likely to leave their jobs if they feel that their assessment was unjust and unfair.

The research has concluded that job satisfaction has a significant impact on attrition. In many private organizations, women attrition has become an important issue. In an organization, private or public, attrition can be significantly reduced by simply gaining the dedication and commitment from employees (Sarkar, Sahoo \& Klasen, 2019). It can be simply done by providing the employees being men or women with satisfactory job. Specifically for women workforce, this can be done easily be providing them with safe and secure job, reasonable workload, good working conditions and positive interpersonal relationships etc. The best way to stray away from destructive effects of attrition or turnover, it is recommended to develop prevention methods in advance to strengthen employees in the organization.

Social Organizational practice has a significant impact on attrition. It has been observed that quality of care is one significant aspect in the retention of women employees in the organizations. It is even more affective in the cases of mothers. As most of the decisions made by working mothers are associated with the social benefits and costs of work and home time. Furthermore, it has been noted in the research of Ko \& Hur (2014) that Organizations that have a healthy social environment and caring centres for children are likely to retain their female employees. It is so because mothers would be less likely to leave their jobs because their child would be comfortable with the care givers. This satisfaction will eventually incline women more towards their job and less incline towards the thought to leave or quit the job (Nilsen, Skipstein \& Demerouti, 2016).

\section{References}

Adeoye, A.O. \& Fields, Z. (2014). Compensation Management and Employee Job Satisfaction: A Case of Nigeria. Journal of Social Sciences, vol.41:3, pp.345-352.

Ahlin, J., Ericson $\square$ Lidman, E., Norberg, A. \& Strandberg, G. (2015). A Comparison of Assessments and Relationships of Stress of Conscience, Perceptions of Conscience, Burnout and Social Support between Healthcare Personnel Working at Two Different Organizations for Care of Older People. Scandinavian Journal of Caring Sciences, vol.29:2, pp.277-287.

Carson, D. B., Wenghofer, E., Timony, P., Schoo, A., Berggren, P., Charters, B. \& Garrett, J. (2016). Recruitment and Retention of Professional Labour: The Health Workforce at Settlement Level. List of Contributors ix Foreword by Tomas Mörtsell xxvii Preface and Acknowledgements xxix Part i Settlement Histories and their Representations, 320. 
Dalle Grave R., Calugi S., Doll H.A. \& Fairburn C.G. (2016). Enhanced Cognitive Behaviour Therapy for Adolescents with Anorexia Nervosa: An Alternative to Family Therapy? Behaviour Research and Therapy. 2013; 51:R9-R12.

Eikhof, D. R. (2016). Knowledge Work and Flexible Working: Helping or Hindering Working Women?. In Handbook on Well-Being of Working Women (pp. 361374). Springer, Dordrecht.

Fox, A. B. \& Quinn, D. M. (2015). Pregnant Women at Work: The Role of Stigma in Predicting Women's Intended Exit from the Workforce. Psychology of Women Quarterly, vol.39:2, pp.226-242.

Gupta, M., Kumar, V. \& Singh, M. (2014). Creating Satisfied Employees through Workplace Spirituality: A Study of the Private Insurance Sector in Punjab (India). Journal of Business Ethics, vol.122:1, pp.79-88.

Gupta, S., Bhaskar, U. (2016). Doing Business in India: Cross-Cultural Issues in Managing Human Resources. Cross Cultural \& Strategic Management, vol.23:1, pp.184-204.

Haque, AU. \& Yamoah, F. (2014). Gender Employment Longevity: IT Staff Response to Organizational Support in Pakistan, International Journal of Academic Research in Business and Social Sciences, vol.4:12, pp.324-347.

Ibarra, H. \& Petriglieri, J. (2016). Impossible Selves: Image Strategies and Identity Threat in Professional Women's Career Transitions. Faculty \& Research Working Paper, INSEAD, The Business School of the World.

Irefin, P. \& Mechanic, M.A. (2014). Effect of Employee Commitment on Organizational Performance in Coca Cola Nigeria Limited Maiduguri, Borno state. Journal of Humanities and Social Science, vol.19:3, pp.33-41.

Karatepe, O.M. \& Shahriari, S. (2014). Job Embeddedness as a Moderator of the Impact of Organizational Justice on Turnover Intentions: A Study in Iran. International Journal of Tourism Research, vol.16:1, pp.22-32.

Kiazad, K., Holtom, B.C., Hom, P.W. \& Newman, A. (2015). Job Embeddedness: A Multifoci Theoretical Extension. Journal of Applied Psychology, vol.100:3, p.641.

Ko, J. \& Hur, S. (2014). The Impacts of Employee Benefits, Procedural Justice and Managerial Trustworthiness on Work Attitudes: Integrated Understanding Based on Social Exchange Theory. Public Administration Review, vol.74:2, pp.176-187. 
Korsakiene, R., Stankeviciene, A., Simelyte, A. \& Talackiene, M. (2015). Factors Driving Turnover and Retention of Information Technology Professionals. Journal of Business Economics and Management, vol.16:1, pp.1-17.

Locke, T. (2016). Cracking the Spheres of Domesticity: How Female Roles as Nurses and Spies in the American Civil War Gave Women the Tools for Future Activism (Doctoral Dissertation).

Masvaure, P., Ruggunan, S. \& Maharaj, A. (2014). Work Engagement, Intrinsic Motivation and Job Satisfaction among Employees of a Diamond Mining Company in Zimbabwe. Journal of Economics and Behavioural Studies, vol.6:6, p.488.

Micke, H. (2015). Causes and Solutions for High Direct Care Staff Turnover. Master of Social Work Clinical Research Papers, School of Social Work. St. Catherine University \& University of St. Thomas St. Paul, Minnesota

Mohanty, A. \& Jena, L. K. (2016). Work-Life Balance Challenges for Indian Employees: Socio-Cultural Implications and Strategies. Journal of Human Resource and Sustainability Studies, vol.4:01, p.15.

Neal, M. B. \& Hammer, L. B. (2017). Working Couples Caring for Children and Aging Parents: Effects on Work and Well-Being. Psychology Press.

Nilsen, W., Skipstein, A. \& Demerouti, E. (2016). Adverse Trajectories of Mental Health Problems Predict Subsequent Burnout and Work-Family Conflict - A Longitudinal Study of Employed Women with Children Followed Over 18 Years. BMC Psychiatry, vol.16:1, p.384.

Olowokere, B.O., Chovwen, C.O. \& Balogun, S.K. (2014). Determinants of Job Hopping Experience among Private and Public Sector Employees' Turnover Intention. IFE PsychologIA: An International Journal, vol.22:2, pp.114-124.

Peltokorpi, V., Allen, D.G. \& Froese, F. (2015). Organizational Embeddedness, Turnover Intentions and Voluntary Turnover: The Moderating Effects of Employee Demographic Characteristics and Value Orientations. Journal of Organizational Behaviour, vol.36:2, pp.292-312.

Robinson, R.N., Kralj, A., Solnet, D.J., Goh, E. \& Callan, V. (2014). Thinking Job Embeddedness not Turnover: Towards a Better Understanding of Frontline Hotel Worker Retention. International Journal of Hospitality Management, vol.36, pp.101-109. 
Rubel, M.R.B. \& Kee, D.M.H. (2015). High Commitment Compensation Practices and Employee Turnover Intention: Mediating Role of Job Satisfaction. Mediterranean Journal of Social Sciences, vol.6:6 S4, p.321.

Saeed, I., Waseem, M., Sikander, S. \& Rizwan, M. (2014). The Relationship of Turnover Intention with Job Satisfaction, Job Performance, Leader Member Exchange, Emotional Intelligence and Organizational Commitment. International Journal of Learning and Development, vol.4:2, pp.242-256.

Sarkar, S., Sahoo, S. \& Klasen, S. (2019). Employment Transitions of Women in India: A Panel Analysis. World Development, vol.115, pp.291-309.

Seidler, A., Thinschmidt, M., Deckert, S., Then, F., Hegewald, J., Nieuwenhuijsen, K. \& Riedel-Heller, S.G. (2014). The Role of Psychosocial Working Conditions on Burnout and its Core Component Emotional Exhaustion-a Systematic Review. Journal of Occupational Medicine and Toxicology, vol.9:1, p.10.

Siebert, S. \& Martin, G. (2016). Managing People and Organizations in Changing Contexts. Routledge Taylor \& Francis Group. Publisher of Humanities, Social Science \& STEM Books

Terera, S.R. \& Ngirande, H. (2014). The Impact of Rewards on Job Satisfaction and Employee Retention. Mediterranean Journal of Social Sciences, vol.5:1, p.481.

William Lee, T., Burch, T.C. \& Mitchell, T.R. (2014). The Story of Why We Stay: A Review of Job Embeddedness. Annu. Rev. Organ. Psychol. Organ. Behav., vol.1:1, pp.199-216.

Williams, J. C., Berdahl, J. L. \& Vandello, J. A. (2016). Beyond Work-Life "Integration". Annual Review of Psychology, vol.67, pp.515-539.

Fahad Abdali is a Ph. D. Scholar in the Department of Public Administration, University of Karachi, Karachi, Pakistan.

Prof. Dr. M. Abuzar Wajidi is a Dean, Faculty of Management Sciences, Barrett Hodgson University, Karachi, Pakistan.

Faraz Ahmed Wajidi is an Associate Professor in Institute of Business and Health Management (IBHM) - Dow University of Health Sciences, Karachi, Pakistan. 